\title{
Sciatic nerve block or not for outpatient total knee arthroplasty? Study protocol for a randomized controlled trial
}

\author{
Laurie $\operatorname{Tran}^{1 *}$ (D), Melissa Barthelemy ${ }^{1}$, Pascal Boileau², Marc Raucoules-Aime ${ }^{1}$, Michel Carles $^{1}$ and \\ Christophe Trojani ${ }^{2}$
}

\begin{abstract}
Background: The number of patients operated on for total knee arthroplasty (TKA) is growing worldwide. Outpatient surgery is defined by a length of stay (LOS) in the hospital of less than $12 \mathrm{~h}$. This can be limited for TKA, with the efficient management of pain and perioperative complications, such as blood loss, affecting a safe hospital discharge. Outpatient TKA with a suitable protocol, including multimodal measures, could improve the success rate of this procedure. Among the main measures, single-shot sciatic nerve block in association with continuous femoral nerve block for pain control needs to be evaluated in outpatient TKA. Furthermore, to promote the safety of the postoperative period and to accelerate rehabilitation, patients who undergo ambulatory TKA could be discharged to a rehabilitation center on the day of surgery to screen adverse events and to optimize the rehabilitation process. This study is designed to assess the benefits of sciatic nerve block in postoperative pain relief for outpatient TKA.

Methods/design: This randomized prospective controlled study will be conducted in the knee unit of the teaching hospital of the Nice university and will include 40 patients undergoing primary unilateral outpatient TKA, discharged the day of surgery to a private rehabilitation center for enhanced recovery after surgery, after a hospital stay of less than $12 \mathrm{~h}$. Before surgery, all patients will receive a continuous femoral nerve block with $2 \mathrm{mg} / \mathrm{ml}$ ropivacaine $20 \mathrm{ml}$, and then patients will be randomly assigned to receive or not receive a single-shot sciatic nerve block with $2 \mathrm{mg} / \mathrm{ml}$ ropivacaine, $20 \mathrm{ml}$. The primary outcome measure is the success rate of outpatient TKA. This rate is defined by patients discharged from the hospital to a rehabilitation center the day of surgery with no rehospitalization due to insufficient pain control before the fifth postoperative day. Secondary outcomes include the incidence of major and minor adverse events during the first five postoperative days and measurement of the quality of recovery using the Knee injury and Osteoarthritis Outcome Score and the new International Knee Society scores plus the Quality of Recovery-40 questionnaire.
\end{abstract}

Discussion: The assessment of anesthesia and rehabilitation protocols enabling major orthopedic surgery, such as TKA, is necessary. This randomized controlled study will address the hypothesis that a suitable multimodal protocol including sciatic nerve block could improve pain control and thus improve the success rate of outpatient TKA.

Trial registration: EudraCT, 2016-000226-19. Registered on 15 April 2016.

Keywords: Total knee arthroplasty, Outpatient procedure, Sciatic nerve block, Randomized controlled study

\footnotetext{
* Correspondence: tran.l@chu-nice.fr

${ }^{1}$ Department of Anesthesiology, Intensive care and Emergency Medicine,

Pasteur 2 Hospital, 30, Voie Romaine, CS 51069, 06001 Nice, Cedex 1, France

Full list of author information is available at the end of the article
}

(c) The Author(s). 2019 Open Access This article is distributed under the terms of the Creative Commons Attribution 4.0 International License (http://creativecommons.org/licenses/by/4.0/), which permits unrestricted use, distribution, and reproduction in any medium, provided you give appropriate credit to the original author(s) and the source, provide a link to the Creative Commons license, and indicate if changes were made. The Creative Commons Public Domain Dedication waiver (http://creativecommons.org/publicdomain/zero/1.0/) applies to the data made available in this article, unless otherwise stated. 


\section{Background}

Total knee arthroplasty (TKA) is commonly performed to relieve pain due to osteoarthritis, to improve knee function, and to increase quality of life [1]. The concept of fast-track surgery described by Henrik Kehlet in 2008 is known to reduce perioperative mortality and morbidity $[2,3]$. Since the last decade, fast-track surgery with multimodal perioperative care has been applied to this major orthopedic procedure to reach an ultimate goal: outpatient TKA surgery [4-6].

In outpatient TKA, patient selection is also strongly recommended [4-6], because preexisting comorbidities and advanced age are associated with a higher prevalence of postoperative complications.

Outpatient surgery is defined by a length of stay (LOS) in the hospital of less than $12 \mathrm{~h} \mathrm{[7],} \mathrm{but} \mathrm{it} \mathrm{can} \mathrm{be} \mathrm{limited}$ for TKA by adequate management of pain $[8,9]$ and other perioperative complications, such as blood loss [10], affecting a safe hospital discharge. For pain control, the efficacy of continuous femoral nerve block in TKA is well documented; it enables a controlled opioid consumption [11-13] and could reduce hospital LOS [14]. The benefits of sciatic nerve block in association with continuous femoral nerve block has been proven recently [15-17], but not in outpatient surgery. Postoperative anemia also limits outpatient procedures $[18,19]$. Therefore, a strategy limiting perioperative blood loss including biological and clinical monitoring is mandatory.

In the published studies on TKA, almost $90 \%$ of patients identified as "outpatients" spent $23 \mathrm{~h}$ in the hospital prior to discharge to their homes [20-22] and could therefore be considered as "inpatients", as they stayed one night in the hospital. In the present study, to obtain a hospital LOS shorter than $12 \mathrm{~h}$, patients will be discharged directly to a rehabilitation center. This strategy ensures complete screening of postoperative complications and allows an enhanced recovery after surgery (ERAS).

Major adverse events or readmissions are not different in outpatient procedures compared to inpatient procedures [21]. Finally, outpatient TKA surgery reduces health care costs [22-24].

This study is designed to assess the benefits of sciatic nerve block in postoperative pain relief for outpatient TKA. We also investigate the incidence of adverse events such as hematoma, anemia, thromboembolism, and surgical site infection in the first 5 postoperative days.

\section{Trial design and methods Study design}

This single-center randomized prospective controlled trial respects the Declaration of Helsinki and is approved by the ethics committee "Sud Mediterranee V" and the French National Drug Security Agency (160095A-31).
Written informed consent will be obtained from each patient before enrollment. This study follows the Consolidated Standards of Reporting Trials (CONSORT) and the Standard Protocol Items: Recommendations for Interventional Trials (SPIRIT) 2013 Statements, Fig. 1 (the SPIRIT checklist is available as Additional file 1) $[25,26]$. The trial is registered in EUDRACT, number 2016-000226-19 (registered on 15 April 2016).

An overview of the trial design is shown in Fig. 2.

\section{Recruitment and consent}

We will recruit 40 patients through the University Institute of Locomotion \& Sports of Pasteur 2 Hospital in Nice, France. Consecutive patients presenting for primary unilateral TKA will be screened for eligibility. Patients not participating in the study will receive usual care (TKA inpatient).

Those willing to participate will be asked for informed consent using an approved consent form.

To be eligible, participants must meet the following inclusion criteria:

- Scheduled primary unilateral TKA

- Acceptance of outpatient procedure

- Patient age above 18 years and under 75 years

- Normal weight or moderate obesity

- American Society of Anesthesiologists (ASA) classification 1-2

- Patients without cognitive disorders having a good level of understanding of outpatient procedure (pain control)

- No major thromboembolic episode in medical history

- No contraindications for anesthesia or analgesia

- Preoperative hemoglobin $>13 \mathrm{~g} / \mathrm{dl}$

Exclusion criteria will include:

- Bilateral TKA

- Revision TKA

- Unicompartmental knee arthroplasty

- Severe (body mass index (BMI) $>35$ ) and morbid (BMI > 40) obesity

- ASA classification 3-4

- Obstructive sleep apnea syndrome

- Hypersensitivity or allergy to anesthesia drugs

- Refusal of the outpatient procedure by the patient

- Emergency surgery

- Anticoagulant therapy

\section{Preoperative surgical evaluation}

To assess pain and disability associated with knee osteoarthritis, the Numeric Rating Scale (NRS), the new Knee Society Scoring (KSS) System [27], and the Knee injury 


\begin{tabular}{|c|c|c|c|c|c|c|c|c|c|c|}
\hline \multirow[b]{3}{*}{$\begin{array}{c}\text { TIMEPOINT } \\
\text { (Day } 0=\text { Day of surgery, } \\
W=\text { week, } M=\text { month) }\end{array}$} & \multicolumn{10}{|c|}{ STUDY PERIOD } \\
\hline & \multirow{2}{*}{$\begin{array}{c}\text { Enrolment } \\
\mathrm{M}-2\end{array}$} & \multirow{2}{*}{$\begin{array}{c}\text { Allocation } \\
\text { Day } 0\end{array}$} & \multicolumn{8}{|c|}{ Post allocation, Intervention delivery and research follow up } \\
\hline & & & D1 & D2 & D3 & D4 & D5 & w4 & мз & M12 \\
\hline \multicolumn{11}{|l|}{ ENROLMENT } \\
\hline \multirow{3}{*}{$\begin{array}{r}\text { - Eligibility screen } \\
\text { - Informed consent } \\
\text { - Allocation }\end{array}$} & $\sqrt{ }$ & & & & & & & & & \\
\hline & $\checkmark$ & & & & & & & & & \\
\hline & $\checkmark$ & & & & & & & & & \\
\hline \multicolumn{11}{|l|}{ INTERVENTION } \\
\hline - Surgery & & $\checkmark$ & & & & & & & & \\
\hline $\begin{array}{r}\text {-Pain Control } \\
\text { (continuous femoral } \\
\text { block) }\end{array}$ & & $\checkmark$ & $\checkmark$ & $\checkmark$ & & & & & & \\
\hline $\begin{array}{l}\text {-Pain control (single } \\
\text { shot sciatic block) }\end{array}$ & & $\checkmark$ & & & & & & & & \\
\hline $\begin{array}{r}\text { Pain control } \\
\text { (multimodal oral } \\
\text { analgesia) } \\
\end{array}$ & & $\checkmark$ & $\checkmark$ & $\checkmark$ & $\checkmark$ & $\checkmark$ & $\checkmark$ & & & \\
\hline \multicolumn{11}{|l|}{ ASSESSMENT } \\
\hline $\begin{array}{r}\text { - Success rate of } \\
\text { outpatient TKA }\end{array}$ & & & & & & & $\checkmark$ & & & \\
\hline $\begin{array}{r}- \text {-Incidence of adverse } \\
\text { events }\end{array}$ & & $\sqrt{ }$ & $\checkmark$ & $\checkmark$ & $\checkmark$ & $\checkmark$ & $\sqrt{ }$ & $\checkmark$ & $\checkmark$ & $\checkmark$ \\
\hline - QoR 40 questionnaire & & & & & & & $\checkmark$ & & $\checkmark$ & $\checkmark$ \\
\hline -IKS and KOOS scores & $\checkmark$ & $\checkmark$ & & & & & & & $\checkmark$ & $\checkmark$ \\
\hline -X Ray evaluation & $\checkmark$ & $\checkmark$ & & & & & & & $\checkmark$ & $\checkmark$ \\
\hline - Knee Range of Motion & $\checkmark$ & $\checkmark$ & & & & & & $\checkmark$ & $\checkmark$ & $\checkmark$ \\
\hline
\end{tabular}

Fig. 1 Outpatient TKA procedure SPIRIT figure: schematic diagram of enrollment, interventions, and assessments of trial participants in outpatient TKA protocol

and Osteoarthritis Outcome Score (KOOS) [28] will be systematically completed for each patient during the preoperative time. Furthermore, X-ray evaluation will include the anterior to posterior (AP) view and lateral and patellar views for each patient, as well as full-length $\mathrm{X}$-rays to evaluate varus and valgus deformities.

\section{Randomization and group allocation}

The objective of this study is to assess a protocol for outpatient TKA including postoperative analgesia optimized to allow same-day discharge to a rehabilitation center. For TKA, all patients usually receive continuous femoral nerve block with $2 \mathrm{mg} / \mathrm{ml}$ ropivacaine. Two groups are defined randomly. Patients who receive sciatic nerve block with $20 \mathrm{ml}$ of ropivacaine $2 \mathrm{mg} / \mathrm{ml}$ are allocated to the "sciatic block group" (BS+). Patients who will not receive sciatic nerve block are allocated to a second group (BS-). Random assignment is performed before surgery using a computer-generated randomization table.

\section{Anesthesia and analgesia}

The "outpatient TKA journey" is represented in Fig. 3. Premedication by oral dose of celecoxib $200 \mathrm{mg}$ [29] and hydroxysine $25 \mathrm{mg}$ will be administered in the surgical care unit. All recruited patients will receive continuous femoral nerve block (under ultrasound guidance [30]) with $2 \mathrm{mg} / \mathrm{ml}$ ropivacaine, $20 \mathrm{ml}$. In the BS+ group, patients will also receive a sciatic nerve block (subgluteal approach [31] under ultrasound guidance) with $2 \mathrm{mg} / \mathrm{ml}$ ropivacaine $20 \mathrm{ml}$. In order to improve quality and duration of the nerve block, intravenously administered (IV) dexamethasone $8 \mathrm{mg}$ will be administered at the time of regional analgesia [32]. Surgery will be performed under spinal anesthesia (L3-L4 level, in lateral decubitus, on the same side as the surgery) with 8 or $10 \mathrm{mg}$ of bupivacaine $5 \mathrm{mg} / \mathrm{ml}$ respectively, for women and men.

For all patients, prophylactic antibiotic treatment with IV cefazolin $2 \mathrm{~g}$ will be given $30 \mathrm{~min}$ before surgery. The prophylactic antibiotic treatment will be continued with oral clindamycin (600 mg every $8 \mathrm{~h}$ ) until postoperative 


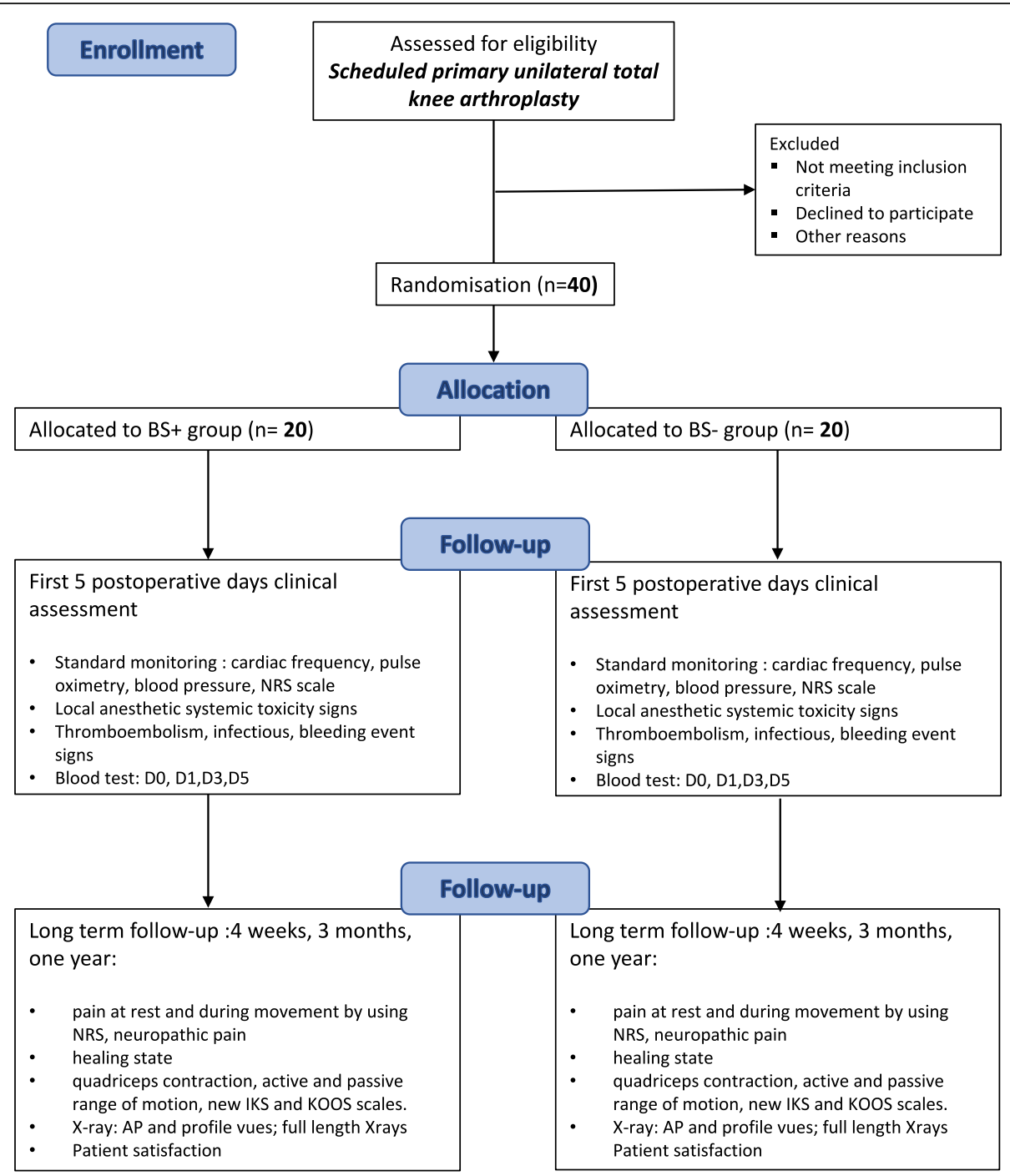

Fig. 2 Overview of study protocol. BS+ group group with sciatic nerve block (single shot) and continuous femoral nerve block, BS- group group with only continuous femoral nerve block

day 1, as suggested by the French Society of Anesthesiology.

The first IV analgesic will be administered after skin incision with paracetamol $1 \mathrm{~g}$ and nefopam $20 \mathrm{mg}$.

\section{Surgical procedure and blood loss treatment strategy}

All patients will receive two infusions of tranexamic acid $10 \mathrm{mg} / \mathrm{kg}$ (before surgery and at the third postoperative hour). A Zimmer NexGen ${ }^{\circ}$ prosthesis will be implanted in all recruited patients. The procedure is performed using a $250 \mathrm{mmHg}$ tourniquet, from skin incision to knee compression dressing, through a medial approach in a varus knee and a lateral approach in a valgus knee. The NexGen prosthesis is postero-stabilized with a fixed polyethylene bearing. The patella will be resurfaced systematically. Femoral, tibial, and patellar components will be cemented systematically with Palacos ${ }^{\ominus}$ gentamicin.
Two intra-articular autotransfusion suction drains will be systematically positioned: the suction drains will be removed after the first passive physiotherapy session (Kinetech ${ }^{\circ}$ ) with dressing refection (semicompressive) at the third postoperative hour. Autotransfusion will be infused if the total blood volume is above $300 \mathrm{ml}$. IV iron (iron hydroxide sucrose complex $300 \mathrm{mg}$ ) will be infused in the post-anesthesia care unit (PACU) and on the second postoperative day.

\section{Postoperative analgesia}

Pain at rest and during movement will be assessed by using the NRS.

Multimodal pain management will include:

- Continuous femoral nerve block with infusion of 2 $\mathrm{mg} / \mathrm{ml}$ ropivacaine by using a perineural patient- 


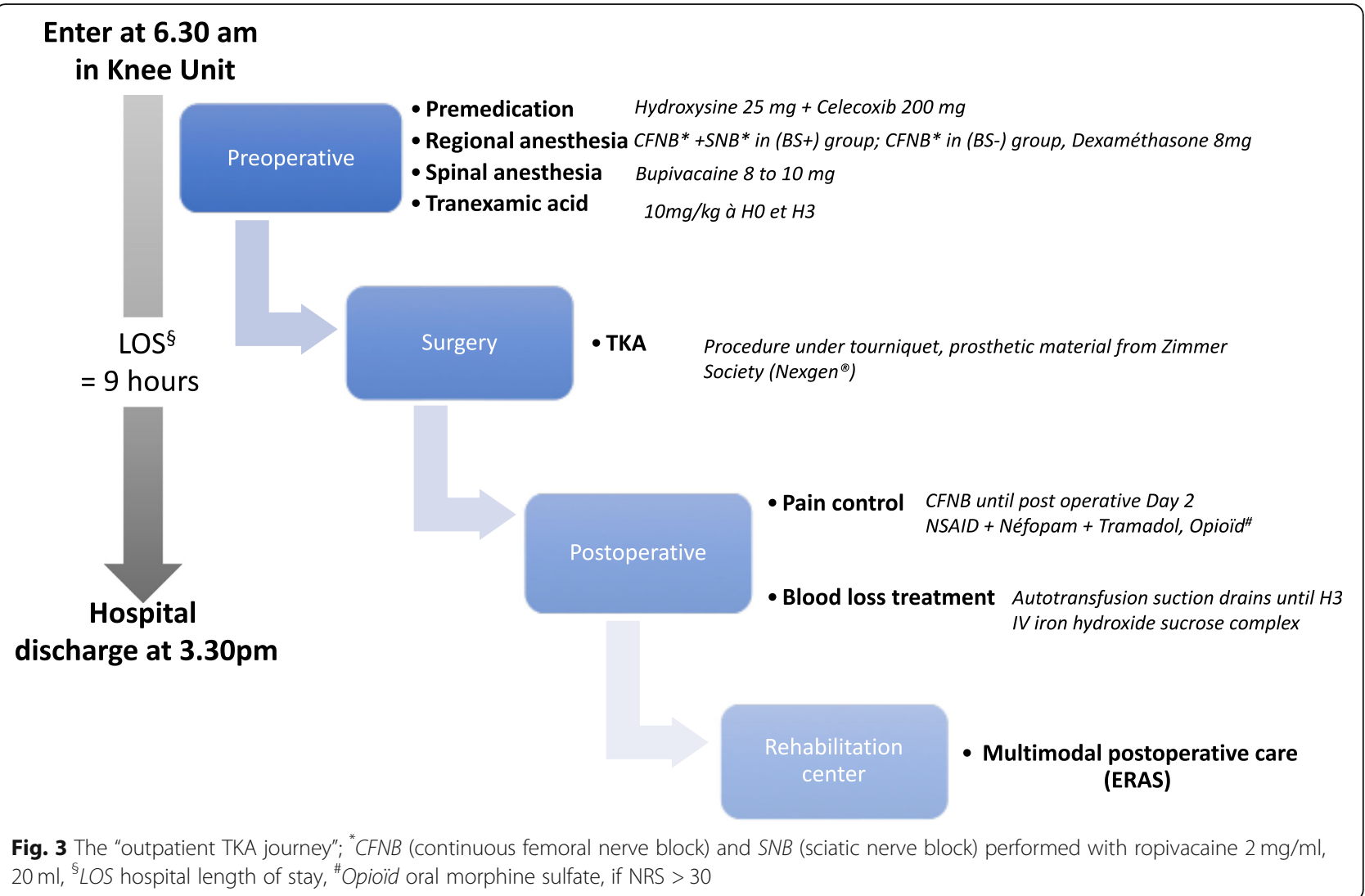

controlled analgesia with continuous infusion $(5 \mathrm{ml} / \mathrm{h})$ and bolus ( $5 \mathrm{ml}$ every $30 \mathrm{~min}$ ). Perineural infusion will run until the second postoperative day.

- Paracetamol $1 \mathrm{~g} / 8 \mathrm{~h}$

- Ketoprofen 100 mg/12 h

A rescue analgesic protocol will be performed if pain control proves to be insufficient (NRS > 30) 20 min after ropivacaine bolus by using IV tramadol $100 \mathrm{mg}$.

If the NRS value remains $>30$ at 20 min after tramadol infusion, oral morphine sulfate $10 \mathrm{mg}$ will be administered to the patient. This analgesic routine will be repeated until NRS $<30$.

\section{Early mobilization}

All patients will be seen by a physiotherapist the day of surgery to start the rehabilitation program with passive physiotherapy and ambulation using a walker: at $3 \mathrm{~h}$ post-surgery, a physiotherapy session will be performed; then the dressing will be changed and the drains will be removed, and the patients will walk with the help of a physiotherapist.

\section{Hospital discharge to a rehabilitation center}

Patients will be discharged to a rehabilitation center on the same day as surgery if the following points are checked and met:
- Ramsay scale $=2$ [33]

- Modified Aldrete scale = 10 [34]

- No adverse events: no postoperative vomiting and nausea, no agitation, no urinary retention, normal blood pressure, normothermia, cardiac frequency $<130 \%$ of preoperative level, NRS $<30$

- Postoperative hemoglobin level $>11 \mathrm{~g} / \mathrm{dl}$

- Standing position and walk with crutches, and Zimmer splint performed by patient

- Patient consent to be discharged from the hospital to the rehabilitation center (written consent also signed by the surgeon and anesthetist performing the procedure)

\section{Follow-up in rehabilitation center}

Patient follow-up will be performed by a multidisciplinary team (surgeon, anesthetist, physical therapist, and nurses).

Standard monitoring from postoperative day 1 to day 5 will be evaluated (cardiac frequency, pulse oximetry, blood pressure, pain with NRS assessment).

Clinical monitoring of the continuous femoral nerve block and the sciatic block according to the French Society of Anesthesiology recommendations will be performed: search for signs of local anesthetic systemic toxicity (central nervous system manifestations with circumoral and/or tongue numbness, metallic taste, 
lightheadedness, dizziness, visual or auditory disturbances, drowsiness, seizure, unconsciousness; cardiovascular manifestations with collapse).

Clinical signs of a thromboembolic event (pain, tenderness, swelling, discoloration in the lower extremities, dyspnea, tachypnea, chest pain), infectious complications, and bleeding (hematoma) will be assessed as well. A complete blood count $(\mathrm{CBC})$ will be performed on postoperative day 1 , day 3 , and day 5 . Patient satisfaction will be evaluated with the Quality of Recovery (QoR)-40 score [35].

\section{Long-term follow-up}

Patients will return for medical and surgical follow-up at 4 weeks, 3 months, and 1 year to assess knee mobility with quadriceps contraction, active and passive range of motion, pain at rest and during movement measured using NRS, and assessment of residual neuropathic pain (DN4 questionnaire) [36]. The new International Knee Society (IKS) and KOOS scores will be systematically completed during the postoperative period. Furthermore, X-ray evaluation will include an AP view, lateral and patellar views, and a full-length X-ray to help assess residual varus and valgus deformities. Patient satisfaction with the outpatient procedure will be assessed using the QoR-40 questionnaire.

\section{Primary outcome evaluation}

The primary outcome is the success rate of outpatient TKA. The success rate is defined by patients discharged from the hospital to a rehabilitation center the day of surgery with no re-hospitalization due to insufficient pain control until the fifth postoperative day.

\section{Secondary outcomes evaluation}

Secondary outcomes include the incidence of adverse events before the fifth postoperative day (including hematoma, anemia, thromboembolism event, surgical site infection) and measurement of quality of recovery using the QoR-40 questionnaire.

\section{Sample size}

Calculation of the sample size was based on previous studies [12, 37].

We assumed that the failure of the outpatient TKA procedure, defined by no discharge the day of surgery or re-hospitalization during the postoperative period due to pain, could reach a peak value of $55 \%$. The association of sciatic nerve block and continuous femoral nerve block could decrease this failure rate up to $15 \%$. Group sample sizes of 19 for each group will achieve 80\% power to detect this difference rate of outpatient procedure failure with an $\alpha$ risk of $5 \%$. We will include 40 patients (20 in each group).

\section{Data analysis}

Data are expressed as mean \pm standard deviation (SD), median (interquartile range (IQR)), or percentage. Continuous variables will be analyzed with a two-sample $t$ test with equal/unequal variance or with a Mann and Whitney $U$ test, if appropriate. A chi-square test or Fischer's exact test will be used for categorical variables. NRS will be analyzed with repeated measures for general linear models and multivariate analysis of variance. A Bonferroni correction will be applied for multiple comparison and subgroup analyses. $P$ values $<0.05$ will be considered significant. All statistical analyses will be performed using R Studio ${ }^{\circ}$, version 1.

\section{Discussion}

This single-center randomized controlled study will provide clinical evidence on the efficacy of a secure protocol for outpatient TKA: the expected results will help to establish the best inclusion criteria for this procedure. Indeed, to anticipate medical adverse events due to patient comorbidities, strict patient selection is mandatory. Therefore, we decided to only include patients under 75 years of age, of ASA classification 1-2, with no comorbidities. Furthermore, to prevent medical complications resulting from surgery, specifically trained teams and a suitable protocol are recommended. Key elements of these protocols include precise preoperative evaluation, standardized analgesic/anesthetic regimens, standardized surgical procedures, and early mobilization. Finally, discharge from the hospital the day of surgery to a rehabilitation center improves the safety of the postoperative period and allows rapid recovery after surgery. It also inspires confidence in patients and health caregivers, even if the term "outpatient" could be challenged, as patients are not discharged to their homes.

This study aims to assess a LOS of less than $12 \mathrm{~h}$ in the hospital after a total knee replacement. If the results show that this protocol is safe, the next step will be to discharge patients with the same inclusion criteria directly to their homes.

\section{Trial organization}

In June 2016 ethical approval was granted by the "Sud Mediterranean V" Regional Research Ethics Committee.

In July 2016 recruitment started.

In September 2016 the first patient was randomized.

In December 2016 the first patient completed the 3 months' follow-up.

In April 2018 recruitment was completed.

In June 2018 the last patient was randomized.

In September 2018 the last patient completed the 3 months' follow-up. Analysis and publication of outcome data proceeded. 


\section{Additional file}

Additional file 1: SPIRIT 2013 checklist: recommended items to address in a clinical trial protocol and related documents. (DOC $145 \mathrm{~kb}$ )

\section{Acknowledgements}

The authors acknowledge and thank the iULS - University Institute of Locomotion \& Sports, Department of Orthopedics \& Sports and the Department of Anesthesiology, Intensive Care and Emergency Medicine members for their support in this research protocol.

\section{Funding}

Not applicable.

\section{Availability of data and materials}

The datasets generated and/or analyzed during the current study are available from the corresponding author on reasonable request.

\section{Authors' contributions}

LT coordinated and developed the study analysis and drafted the manuscript. $C T$ conceived the study and participated in its design and coordination, performed all surgeries, participated in the development of the study analysis, and helped in drafting the manuscript. MB, MC, and PB participated in the conception of the study. All authors read and approved the final manuscript.

\section{Ethics approval and consent to participate}

This manuscript report study protocol involving human participants and human data. This study protocol is compiled in accordance with the Consolidated Standards of Reporting Trials Guidelines [38, 39]. This study was approved by the ethics committee of the French "SUD MEDITERRANEE V" and French National Drug Security Agency (160095A-31). The trial is registered in EUDRACT, number 2016-000226-19 (15 April 2016). Written informed consent will be obtained from all subjects.

\section{Consent for publication}

Not applicable.

\section{Competing interests}

The authors declare that they have no competing interests.

\section{Publisher's Note}

Springer Nature remains neutral with regard to jurisdictional claims in published maps and institutional affiliations.

\section{Author details}

'Department of Anesthesiology, Intensive care and Emergency Medicine, Pasteur 2 Hospital, 30, Voie Romaine, CS 51069, 06001 Nice, Cedex 1, France. ${ }^{2}$ Department of Orthopedics \& Sports, iULS - University Institute of Locomotion \& Sports, Pasteur 2 Hospital, 30, Voie Romaine, CS 51069, 06001 Nice, Cedex 1, France.

Received: 15 February 2018 Accepted: 17 December 2018

Published online: 08 January 2019

\section{References}

1. Skou ST, Roos EM, Laursen MB, Rathleff MS, Arendt-Nielsen L, Simonsen O, et al. A randomized, controlled trial of total knee replacement. N Engl J Med. 2015:373:1597-606

2. Kehlet $\mathrm{H}$, Wilmore DW. Evidence-based surgical care and the evolution of fast-track surgery. Ann Surg. 2008;248:189-98.

3. Holm B, Kehlet H. Rehabilitation after total knee arthroplasty. Ugeskr Laeger. 2009;171:691-4.

4. Argenson J-NA, Husted H, Lombardi A, Booth RE, Thienpont E. Global forum: an nternational perspective on outpatient surgical procedures for adult hip and knee reconstruction. J Bone Joint Surg Am. 2016:98:e55.

5. Machin JT, Phillips S, Parker M, Carrannante J, Hearth MW. Patient satisfaction with the use of an enhanced recovery programme for primary arthroplasty. Ann R Coll Surg Engl. 2013;95:577-81.
6. Gromov K, Kjærsgaard-Andersen P, Revald P, Kehlet H, Husted H. Feasibility of outpatient total hip and knee arthroplasty in unselected patients: a prospective 2-center study. Acta Orthop. 2017;88:516-21.

7. Goyal N, Chen AF, Padgett SE, Tan TL, Kheir MM, Hopper RH, et al. Otto Aufranc Award: a multicenter, randomized study of outpatient versus inpatient total hip arthroplasty. Clin Orthop Relat Res. 2017;475:364-72.

8. Rawal N, Hylander J, Nydahl PA, Olofsson I, Gupta A. Survey of postoperative analgesia following ambulatory surgery. Acta Anaesthesio Scand. 1997:41:1017-22

9. Gerbershagen HJ, Aduckathil S, van Wijck AJ, Peelen LM, Kalkman CJ, Meissner W. Pain intensity on the first day after surgery: a prospective cohort study comparing 179 surgical procedures. Anesthesiol J Am Soc Anesthesiol. 2013:118:934-44.

10. Sinclair KC, Clarke HD, Noble BN. Blood management in total knee arthroplasty: a comparison of techniques. Orthopedics. 2009:32:19.

11. Paul JE, Arya A, Hurlburt L, Cheng J, Thabane L, Tidy A, et al. Femoral nerve block improves analgesia outcomes after total knee arthroplasty: a metaanalysis of randomized controlled trials. Anesthesiology. 2010;113:1144-62

12. Chan E-Y, Fransen M, Parker DA, Assam PN, Chua N. Femoral nerve blocks for acute postoperative pain after knee replacement surgery. Cochrane Database Syst Rev. 2014;5:CD009941.

13. Liu SS, Richman JM, Thirlby RC, Wu CL. Efficacy of continuous wound catheters delivering local anesthetic for postoperative analgesia: a quantitative and qualitative systematic review of randomized controlled trials. J Am Coll Surg. 2006;203:914-32.

14. Mclsaac DI, McCartney CJ, van Walraven C. Peripheral nerve blockade for primary total knee arthroplasty: a population-based cohort study of outcomes and resource utilization. Anesthesiology. 2017;126:312-20.

15. Abdallah FW, Chan WW, Gandhi R, Koshkin A, Abbas S, Brull R. The analgesic effects of proximal, distal, or no sciatic nerve block on posterior knee pain after total knee arthroplasty: a double-blind placebo-controlled randomized trial. J Am Soc Anesthesiol. 2014:121:1302-10.

16. Abdallah FW, Madjdpour C, Brull R. Is sciatic nerve block advantageous when combined with femoral nerve block for postoperative analgesia following total knee arthroplasty? A meta-analysis. Can J Anaesth J Can Anesth. 2016:63:552-68.

17. Amundson AW, Johnson RL, Abdel MP, Mantilla CB, Panchamia JK, Taunton $\mathrm{MJ}$, et al. A three-arm randomized clinical trial comparing continuous femoral plus single-injection sciatic peripheral nerve blocks versus periarticular injection with ropivacaine or liposomal bupivacaine for patients undergoing total knee arthroplasty. Anesthesiology. 2017;126:1139-50.

18. Irisson E, Kerbaul F, Parratte S, Hémon Y, Argenson J-N, Rosencher N, et al. Perioperative management based on kinetics of bleeding during total primary arthroplasty. Ann Fr Anesth Reanim. 2013;32:170-4.

19. Agence Française de Sécurité Sanitaire des Produits de Santé (AFSSAPS). Transfusion of erythrocyte substitutes: products, indications, alternatives General methods and recommendations. Transfus Clin Biol J Soc Francaise Transfus Sang. 2002;9:333-56.

20. Bovonratwet $P$, Webb ML, Ondeck NT, Lukasiewicz AM, Cui JJ, McLynn RP, et al. Definitional differences of "outpatient" versus "inpatient" THA and TKA can affect study outcomes. Clin Orthop. 2017:475:2917-25.

21. Kolisek FR, McGrath MS, Jessup NM, Monesmith EA, Mont MA. Comparison of outpatient versus inpatient total knee arthroplasty. Clin Orthop Relat Res. 2009;467:1438-42

22. Lovald ST, Ong KL, Malkani AL, Lau EC, Schmier JK, Kurtz SM, et al. Complications, mortality, and costs for outpatient and short-stay total knee arthroplasty patients in comparison to standard-stay patients. J Arthroplast. 2014;29:510-5

23. Ilfeld BM, Mariano ER, Williams BA, Woodard JN, Macario A. Hospitalization costs of total knee arthroplasty with a continuous femoral nerve block provided only in the hospital versus on an ambulatory basis: a retrospective, case-control, cost-minimization analysis. Reg Anesth Pain Med. 2007;32:46-54

24. Huang A, Ryu J-J, Dervin G. Cost savings of outpatient versus standard inpatient total knee arthroplasty. Can J Surg J Can Chir. 2017;60:57-62.

25. Chan A-W, Tetzlaff JM, Altman DG, Laupacis A, Gøtzsche PC, Krleža-Jerić K, et al. SPIRIT 2013 statement: defining standard protocol items for clinical trials. Ann Intern Med. 2013:158:200-7.

26. Chan A-W, Tetzlaff JM, Gøtzsche PC, Altman DG, Mann H, Berlin JA, et al. SPIRIT 2013 explanation and elaboration: guidance for protocols of clinical trials. BMJ. 2013;346:e7586. 
27. Debette C, Parratte S, Maucort-Boulch D, Blanc G, Pauly V, Lustig S, et al. French adaptation of the new Knee Society Scoring System for total knee arthroplasty. Orthop Traumatol Surg Res OTSR. 2014;100:531-4.

28. Ornetti P, Parratte S, Gossec L, Tavernier C, Argenson J-N, Roos EM, et al. Cross-cultural adaptation and validation of the French version of the Knee injury and Osteoarthritis Outcome Score (KOOS) in knee osteoarthritis patients. Osteoarthr Cartil. 2008;16:423-8.

29. Recart A, Issioui T, White PF, Klein K, Watcha MF, Stool L, et al. The efficacy of celecoxib premedication on postoperative pain and recovery times after ambulatory surgery: a dose-ranging study. Anesth Analg. 2003;96:1631-5 table of contents.

30. Bouaziz H, Aubrun F, Belbachir A, Cuvillon P, Eisenberg E, Jochum D, et al. Ultrasound-guided regional anesthesia. Ann Fr Anesth Reanim. 2013;32: e119-20.

31. Bruelle P, Muller L, Bassoul B, Eledjam JJ. Block of the sciatic nerve. Cah Anesthesiol. 1994;42:785-91.

32. Desmet M, Braems H, Reynvoet M, Plasschaert S, Van Cauwelaert J, Pottel H, et al. I.V. and perineural dexamethasone are equivalent in increasing the analgesic duration of a single-shot interscalene block with ropivacaine for shoulder surgery: a prospective, randomized, placebo-controlled study. $\mathrm{Br} J$ Anaesth. 2013;111:445-52.

33. Riker RR, Picard JT, Fraser GL. Prospective evaluation of the SedationAgitation Scale for adult critically ill patients. Crit Care Med. 1999;27:1325-9.

34. Aldrete JA, Kroulik D. A postanesthetic recovery score. Anesth Analg. 1970; 49:924-34.

35. Myles PS, Weitkamp B, Jones K, Melick J, Hensen S. Validity and reliability of a postoperative quality of recovery score: the QoR-40. BJA Br J Anaesth. 2000;84:11-5

36. Bouhassira D, Attal N, Alchaar H, Boureau F, Brochet B, Bruxelle J, et al. Comparison of pain syndromes associated with nervous or somatic lesions and development of a new neuropathic pain diagnostic questionnaire (DN4). Pain. 2005;114:29-36.

37. Husted H, Hansen HC, Holm G, Bach-Dal C, Rud K, Andersen KL, et al. What determines length of stay after total hip and knee arthroplasty? A nationwide study in Denmark. Arch Orthop Trauma Surg. 2010;130:263-8.

38. Moher D, Schulz KF, Altman DG. The CONSORT statement: revised recommendations for improving the quality of reports of parallel-group randomised trials. Lancet Lond Engl. 2001;357:1191-4.

39. Schulz KF, Altman DG, Moher D, CONSORT Group. CONSORT 2010 Statement: Updated guidelines for reporting parallel group randomised trials. J Clin Epidemiol. 2010;63:834-40.

Ready to submit your research? Choose BMC and benefit from:

- fast, convenient online submission

- thorough peer review by experienced researchers in your field

- rapid publication on acceptance

- support for research data, including large and complex data types

- gold Open Access which fosters wider collaboration and increased citations

- maximum visibility for your research: over $100 \mathrm{M}$ website views per year

At $\mathrm{BMC}$, research is always in progress.

Learn more biomedcentral.com/submissions 